\section{Online First publication}

Springer-Verlag and the editors of the Environmental Engineering and Policy are pleased to announce a new service for our authors and readers: Online First, the immediate online publication of all accepted papers as soon as the authors have returned the corrected proofs. Whereas the fully electronic versions of the Environmental Engineering and Policy used to appear at the same time as the print journal, from now on the electronic version of all articles will be available to subscribers via the Internet weeks before the printed version appears. This means an enormous reduction in publication time. It will no longer be necessary for manuscripts to wait until the "next available issue".

As each paper is ready for publication, it will be published on the Web with its own publication date as follows: "Published online: < date when placed on Springer's LINK server $>$ ". Each article will receive an international identification code, the "Digital Object Identifier" (DOI), which is registered with the International DOI Foundation and is unique, like the ISBN for books or the ISSN for periodicals. Contributions published Online First are citable by journal title and DOI. The print version will also have the final page numbers, the DOI and the online publication date. Furthermore, the DOI is linked to the URL (Uniform Resource Locator) and the bibliography when the printed issue is released. The DOI is never changed and can be used, for example, to create hyperlinks between Online First articles.
Online First articles appear in their final form. Therefore, papers cannot be changed or withdrawn after electronic publication. Any corrections that might be necessary have to be made in an Erratum, which will be hyperlinked to the article.

Each article will be announced in LINK alert, which is a free alerting service (http://link.springer.de/alert). A table of contents showing all papers that have been accepted for publication in the Environmental Engineering and Policy but not yet printed can be found via the Springer Web page:

\section{http://link.springer.de/link/service/journals/ 10022/tocs.htm}

or http://link.springer-ny.com/link/service/journals/ 10022/tocs.htm

by clicking Online First.

The Editor-in-Chief Springer-Verlag 